This item was submitted to Loughborough's Research Repository by the author.

Items in Figshare are protected by copyright, with all rights reserved, unless otherwise indicated.

\title{
Latent profile analysis of the physical self-description among Chinese
}

\section{Adolescents}

\section{PLEASE CITE THE PUBLISHED VERSION}

http://dx.doi.org/10.1007/s12144-014-9257-y

\section{PUBLISHER}

(C) Springer Verlag

\section{VERSION}

AM (Accepted Manuscript)

\section{PUBLISHER STATEMENT}

This work is made available according to the conditions of the Creative Commons Attribution-NonCommercialNoDerivatives 4.0 International (CC BY-NC-ND 4.0) licence. Full details of this licence are available at: https://creativecommons.org/licenses/by-nc-nd/4.0/

\section{LICENCE}

CC BY-NC-ND 4.0

\section{REPOSITORY RECORD}

Wang, C.K. John, Yanlin Sun, Woon-Chia Liu, Jiaxin Yao, and Do Young Pyun. 2019. "Latent Profile Analysis of the Physical Self-description Among Chinese Adolescents". figshare. https://hdl.handle.net/2134/20869. 
1 Running Head: PHYSICAL SELF-DESCRIPTION PROFILES

2

3

4

5

6

7

8

9 Latent Profile Analysis of the Physical Self-Description among Chinese Adolescents

10

11

12

13

14

15

16

17

18

19

20

21 
Abstract

2 The purposes of this study were to validate the Physical Self-Description Questionnaire (PSDQ-

3 S) and examine the physical self-description profiles using Latent Profile Analysis with a

4 Chinese sample. A total of 744 secondary school students in China took part in the study. While

5 the results provided support for internal reliability and discriminant validity of the PSDQ-S, they

6 indicated that convergent validity required further testing. In addition, three distinct profiles were

$7 \quad$ identified with unique physical self-concept and different levels of physical activity participation.

8 The study showed that the PDSQ-S is useful in differentiating groups of adolescents with

9 different levels of physical self-concept.

10 Keywords: PSDQ-S; latent profile analysis, confirmatory factor analysis, adolescents 

In education setting, a positive self-concept is an influential predictor of significant

3 outcomes such as academic achievement, psychological well-being, and motivation (Marsh,

4 1988; Paradise \& Kernis, 2002). In sport and physical education setting, physical self-concept is

5 even more important as it has been found to be a significant indicator of health outcomes such as

6 physical activity (Fox, 2000; Sonstroem, Harlow, \& Josephs, 1994), physical fitness (Marsh,

7 1996; Marsh \& Redmayne, 1994; van Vorst, Buckworth, \& Mattern, 2002), eating behaviour

8 (Monthuy-Blanc, Maïano, Morin, \& Stehan, 2012), and well being (Paradise \& Kernis, 2002). In

9 a recent review of 113 studies with 128 effect sizes by Spence and his colleagues (Spence,

10 McGannon, \& Poon, 2005), a reciprocal effect of self-esteem was also found that participation in 11 exercise had a positive effect on global self-esteem or self-concept $(d=.23, S E=.02)$. Change in 12 physical fitness and type of programme were two significant moderators of the effect of exercise

13 on global self-esteem. This supports that exercise participation results in significant

14 improvements in global self-esteem. The exercise and self-esteem model used by Spence et al.

15 (2005) was developed on a multifaceted hierarchical concept of self-concept.

There is general consensus that self-concept is the conscious perceptions that individuals

17 have of themselves and include both descriptive and evaluative content (Harter, 1996). Self-

18 concept has been widely accepted as a multifaceted and hierarchically organised structure, based

19 upon the model proposed by Shavelson, Hubner, and Stanton (1976). A multidimensional

20 approach is preferred over traditional approaches (unidimensional) because it recognises that

21 global self-concept arises from multiple sources and across different domains (Marsh, Hey,

22 Roche, \& Perry, 1997). These domains could be social, academic, physical and occupational.

23 Within each domain, there could be numerous subdomains that represent the inferences about 
1 oneself concerning his or her competencies in more specific contexts. The global self-concept is

2 seen as relatively stable compared with domain and subdomain-level self-evaluations.

3 One advantage of the Shavelson et al.'s (1976) model is that it allows researchers to

4 better understand self-concepts study self-concept in a single domain and yet maintain the

5 relevance of the domain to global self-concept. Thus many domain specific measures of self-

6 concepts were designed to differentiate self-concepts with regard to different domains. For

7 example, Marsh and his colleagues (Marsh, Richards, Johnson, Roche, \& Tremayne, 1994)

8 developed the Physical Self-Description Questionnaire (PSDQ) to measure self-concept specific

9 in the physical domain.

10 The original PSDQ contains 70 items with 11 self-concept factors: strength, body fat,

11 activity, endurance and fitness, sport competence, coordination, health, appearance, flexibility,

12 global physical self-worth, and global esteem. When used with other measures or inventories, the

13 PSDQ is often perceived as too long and take too long to complete for applied research. To

14 address this concern, Marsh and his colleagues (Marsh, Martin, \& Jackson, 2010) recently

15 constructed a short version of the Physical Self-Description Questionnaire (PSDQ-S). The 40-

16 item PSDQ-S retains the same factor structure and reliability of the original 70-item PSDQ

17 (Marsh, 1996; Marsh et al., 1994). They provided strong evidence for the reliability, invariance,

18 convergent and discriminant validity of the subscales.

19 Since the development of the short version, not many studies have validated the

20 applicability of the PSDQ-S to other countries and different cultures, particularly, non-English

21 speaking countries with a collectivistic culture. There is a need to examine the psychometric

22 properties of the PSDQ-S when use in a new population. 
Typically, research in this area often uses a variable-centered approach that compares the

2 structure of physical self-concept across elite athletes and physical education students (e.g.,

3 Marsh et al., 1997), age and sex effects (e.g., MaÔano, Ninot, \& Bilard, 2004), and PE major and

4 non PE major students (e.g., Chung, 2003). Recently, Marsh and his colleagues (Marsh, Lüdtke,

5 Trautwein, \& Morin, 2009) propose the use of latent profile analysis (LPA) to explore a person-

6 centered approach to the study of multi-dimensional aspects of academic self-concept. Using this

7 approach, homogenous grouping of students with similar profiles of academic self-concept can

8 be identified and the profiles can then be validated across different correlates.

LPA focuses on grouping individuals with similar characteristics based on the values on

10 the indicator variables. It is similar to the traditional cluster analysis methods. However, cluster

11 analysis is an exploratory and LPA is a model-based approach whereby the researcher can

12 hypothesize a statistical model for the population from which the sample is drawn. The results of

13 the LPA provide the statistical likelihood of each variable and the probability of the group

14 membership and there are several fit indexes that allow model comparisons and informed

15 choices can be made (Marsh et al., 2009). Thus, LPA is a better approach for profiling

16 individuals, compared to the traditional cluster analysis.

\section{Purposes of the Current Study}

18 The first purpose of this study was to validate the PSDQ-S with a Chinese sample.

19 Specifically, we sought to examine reliability and validity (convergent and discriminant) of the

20 subscales in PSDQ-S. The second purpose was to examine the physical self-description profiles

21 among Chinese adolescents using a LPA approach. Finally, the study sought to validate the latent

22 profiles with the level of physical activity participation among the sample. 


\section{Method}

\section{Participants}

A total of 744 secondary school students from four schools in China were recruited for

4 the study. The students were aged from 11 to 16 years $(M=13.29, S D=.94)$. There were 271

5 males and 473 females. They were representative of diverse socio-economic backgrounds.

\section{Procedures}

$7 \quad$ After securing permission from the head teachers, the heads of PE department of the

8 schools were contacted, and arrangements for survey administration were made. Administration

9 of the questionnaires took place in quiet classroom conditions under the supervision of one of the

10 researcher. Students were told that their participation in the study was voluntary, and they were

11 free to withdraw at any time and were assured that their responses would be kept confidential.

12 All students gave informed consent and took about 10 minutes to complete the PSDQ-S

13 administered at the beginning of their PE lessons. Ethical approval was granted from the host

14 University’s Institutional Review Board.

\section{Measures}

16 Physical self-description questionnaire - Short form. The PSDQ-S has 40 items that

17 measure nine specific domains of components of physical fitness and competence (i.e., strength,

18 body fat, activity, endurance/fitness, sports competence, coordination, health, appearance, and

19 flexibility) and two global components (i.e., global physical competence and global self-esteem).

20 In this study, the PDSQ-S was translated to Chinese using a forward and backward translation

21 technique (Brislin, 1990). First, a local Chinese who is bilingual (Chinese and English) translated

22 the questionnaire from English to Chinese. Thereafter, a Singaporean Chinese whom first

23 language is English and well versed in Chinese did a back translation from Chinese to English. 
1 The back-translate English version was compared with the original questionnaire. Both

2 translators are experts in sport psychology. Participants' responses to each item were scored

3 using a 5-point Likert scale ranged from "strongly disagree" (1) to "strongly agree" (5).

4 Physical activity participation. There were two items measuring the frequency of

5 physical activity participation and total number of hours per week involved in physical activity.

6 The frequency of participation ranged from 1 to $4(1=$ occasionally, $2=$ once or twice per week,

$73=$ three to four times per week, and $4=$ five or more times a week). The duration of physical

8 activity participation was made into a 4-point scale $(1=$ less than one hour, $2=$ one to three

9 hours, $3=$ three to six hours, and $4=$ more than six hours).

\section{Data Analysis}

11 In the initial analysis, the descriptive statistics and internal consistency coefficients of the main

12 variables were computed. We examined the internal consistency for each subscale of the PSDQ-

13 S by calculating the rho's coefficients and alpha coefficients. A composite reliability coefficient

14 (rho) of greater than .60 is considered acceptable (Bagozzi \& Yi, 1988), whereas alpha values of

15 greater than .70 is considered satisfactory (Nunnally \& Bernstein, 1995). Cronbach's (1951)

16 alpha coefficients are based on the assumption that there are no measurement error covariances,

17 probably resulting in a bias at the population level (Raykov, 1998). The use of the rho's

18 coefficient corrects for this "bias". Raykov (1998) has demonstrated that Cronbach's alpha may

19 over- or under-estimate scale reliability and for this reason, rho is now preferred and may lead to

20 higher estimates of true reliability. For convergent validity of the measures, we computed the

21 average variance extracted (AVE) values for each scale. The AVE index is a measure of the

22 shared or common variance in a latent variable, that is, the amount of variance that is captured by

23 the latent variable in relation to the amount of variance due to measurement error (Dillion \& 
1 Goldstein, 1984). This provides a measure of convergent validity, and a value greater than .50 is

2 considered acceptable (Fornell \& Larcker, 1981). For discriminant validity, the confidence

3 intervals of the latent factor correlation between each pair of factors were examined $(\phi-$

4 coefficients). If the correlations are significantly less than unity, discriminant validity of the

5 measure is supported (Bagozzi, 1981).

6 We conducted a confirmatory factor analyses (CFA) on the 11-factor measurement model

7 of PSDQ-S, proposed by Marsh et al. (2009). The CFA was conducted using EQS for Windows

86.2 (Bentler \& Wu, 1998) with maximum likelihood estimates derived from covariance matrices.

9 Multiple indices of fit provided by EQS were examined to evaluate the adequacy of the models:

10 Satorra-Bentler scaled chi-square statistic, the robust non-normed fit index (NNFI), the robust

11 comparative fit index (CFI), the robust Bollen's incremental fit index (IFI), and the root mean

12 square error of approximation (RMSEA) and its confidence intervals. Typically, for these fit

13 indices, values greater than .95 were considered satisfactory (Hu \& Bentler, 1999). The RMSEA

14 was based on the analysis of residuals and compensates for the effects of model complexity. For

15 this, $\mathrm{Hu}$ and Bentler (1999) recommended the cut-off of .06.

Additionally, a LPA was conducted using Mplus 7.0 (Muthén, 2001; Muthén \& Muthén,

17 2004). All the mean scores of the 11 subscales of the PDSQ-S were used as the grouping

18 variables. The analyses were conducted from one to eight groups in order to select the best

19 solution based on their fit statistics. The algorithm used was integration, and the number of initial

20 stage randomly started at 2000 with 200 stages of final stage optimizations. The maximum

21 number of iterations was 500, and the estimator used was Multivariate Linear Regression

22 (MLR). The indices used to evaluate the fit of the model were entropy statistics (Muthén \&

23 Muthén, 2004), Akaike's information criterion (AIC; Akaike, 1987), Bayesian information 
1 criterion (BIC, Schwartz, 1978), sample-size adjusted BIC, and Lo-Mendell-and Rubin

2 likelihood ratio test (LMR; Lo, Mendell, \& Rubin, 2001). The entropy statistics higher than .60

3 indicates high classification utility (see Pastor, Barron, Miller, \& Davis, 2007). Lower values of

4 both AIC and BIC are indicators of better model fit. The LMR test was used to compare an

5 estimated model with a model whose class was one less than the estimated model. A small $p$ -

6 value associated with the LMR test supports the retention of a more complex solution with $\mathrm{k}$

7 clusters (Pastor et al., 2007). In addition, we also examined the models with number of groups

8 that had less than $1 \%$ and less than $5 \%$ of the cases. It is suggested that solutions with small

9 number of cases may not be feasible (Marsh et al., 2009).

10 After the cluster profiles have been determined, a MANOVA was conducted using the

11 cluster as grouping variable and the frequency and duration of physical activity participation as

12 the outcome variables. This helped to verify the concurrent validity of the cluster solution.

\section{Results}

The mean scores, standard deviations, reliability coefficients, skewness and kurtosis for

15 the PDSQ-S scales are shown in Table 1. All the PDSQ-S subscales had adequate internal

16 consistency of alpha coefficients equal or higher than .70, and rho coefficients higher than .60.

17 This indicates that all the subscales had satisfactory reliability. Univariate skewness and kurtosis

18 statistics indicated that the observed variables in the main sample were approximately normal

19 (within \pm 1.00 ), except for sports competence. In terms of convergent validity, eight out of the

20 eleven scales showed unsatisfactory AVE values. The results showed that several PDSQ-S

21 subscales were highly correlated with each other. The latent factor correlations and its

22 confidence intervals between each pair of scale are shown in Table 2 . All the correlation

23 coefficients and confidence intervals were significantly lower than 1, except for the confidence 
1 intervals between sports competence and endurance (with $90 \%$ CI of SE [.78, 1.02]). In general,

2 the scales of the PDSQ-S had adequate discriminant validity (Bagozzi, 1981). The results of the

3 CFA on the measurement model of the PDSQ-S showed that the model fit the data adequately

$4 \quad\left(\right.$ Scaled $\chi^{2}=1188.43, d f=685$; robust $\mathrm{NNFI}=.934$, robust $\mathrm{CFI}=.942$; robust $\mathrm{IFI}=.943$,

$5 \quad$ RMSEA $=.031,90 \%$ CI of RMSEA [.028, .034]).

6 The results of the latent profile analysis are presented in Table 3. From the values of AIC,

7 BIC, and SSA-BIC, it can be seen that when the clusters increased from three to four clusters

8 onwards, there were only marginal decrease (less than $0.5 \%$ decrease in SSA-BIC). The entropy

9 values for all the models were greater than .70. The $p$ values of the LMR for K versus K-1

10 classes were only significant for two- to three-group solutions. That is, the four-group solution

11 was not significantly better than the three-group solution. Based on the pLMR and values of AIC,

12 BIC and SSA-BIC, it was clear that a three-group solution was the best.

13 Figure 1 shows the profiles of the three clusters. $\mathrm{Z}$ scores of $+/-.50$ or greater were used

14 as criteria to describe whether a group scored relatively 'high' or 'low' in comparison to their

15 peers. In Cluster 1 , there were $35 \%$ of the participants $(N=260)$, with $53.8 \%$ males and $46.2 \%$

16 females. The unique characteristics of this group was having all PDSQ-S scores higher than Z

17 scores of .50 , except for body fat $(Z=.42)$ and health $(Z=.37)$. Cluster 2 consisted of $17.5 \%$ of

18 the sample $(N=130)$. This female-dominated group $(84.6 \%)$ had the characteristics of low

19 PDSQ-S scores of lower than $\mathrm{Z}=-.50$. Cluster $3(47.5 \%$ of the sample, $N=354)$ appeared to

20 have a moderate PDSQ-S scores with $31.4 \%$ males and $68.6 \%$ females.

21 The results of the MANOVA using cluster as grouping variables and physical activity

22 frequency and duration as outcome variables showed that the three cluster differed significantly

23 in physical activity participation (Pillai's Trace $=.88, F[22,1464]=52.47, p<.001, \eta_{\mathrm{p}}{ }^{2}=.44$ ). 
1 The results of the first ANOVA showed that the three clusters differed significantly in their

2 duration of physical activity participation, $F(2,741)=34.49, p<.001, \eta_{\mathrm{p}}{ }^{2}=.08$. Follow-up tests

3 using Tukey's HSD showed that Cluster 1 reported highest duration of weekly physical activity

4 duration, followed by cluster 3. Cluster 2 had the lowest score in the duration of physical activity

5 participation. The pairwise comparisons indicated all the differences among the three clusters

6 were significantly $(p s<.05)$. Similarly, the results on the frequency of physical activity

7 participation differed among the three clusters $\left(F[2,741]=65.39, p<.001, \eta_{\mathrm{p}}{ }^{2}=.15\right)$. Again,

8 Cluster 1 had the highest score in the frequency of physical activity participation, and Cluster 2

9 reported lowest physical activity frequency (see Table 4). The pairwise comparisons indicated all

10 the differences among the three clusters were significantly $(p s<.05)$.

\section{Discussion}

The present study was designed to validate the PSDQ-S among Chinese adolescents and

13 to examine the LPA of the physical self-concept, measured by the PSDQ-S. In this study, we

14 examined the internal consistency, convergent validity, and discriminate validity of the subscales

15 in PSDQ-S. In terms of reliability, all the scales of the PSDQ-S were found to have adequate

16 internal consistency. In addition to Cronbach's (1951) coefficient alpha, we also computed the

17 "unbiased" rho's coefficients which also supported the reliability of the subscales.

18 The test of discriminant validity suggested that all the confidence intervals between the

19 scales of the PSDQ-S, except between sports competence and endurance, were less than 1.00.

20 Therefore, it was deeded discriminant validity of the PSDQ-S was generally supported.

21 However, the results showed convergent validity was not supported as AVEs of most of the

22 PDSQ-S scales did not meet the cut-off, indicating more than a half of its total variance was

23 derived from measurement errors (Fornell \& Larcker, 1981). 
Marsh et al. (2010) has shown that PDSQ-S has strong construct validity in terms of convergent validity, discriminant validity, and reliability. They also support the invariance measurement models across different samples. This study uses a different approach to the test of

4 construct validity by calculating the CI of the latent factor correlations, AVE, and rho, and

5 provides support to discriminant validity and reliability of the PDSQ-S. However, there seems to

6 be some issues with convergent validity using the AVE approach. As this is the first study to

7 examine the AVE of the PDSQ-S, it suggests that replication studies are needed to further

8 examine convergent validity of the PDSQ-S. It should be noted that the multitrait-multimethod

9 used by Marsh et al. essentially uses the correlation coefficients of different traits and a large

10 sample size. The judgement nature of the MTMM means that different researchers could arrive 11 at different conclusions (Cole, 1987).

12 The findings of the present study show that there are at least three groups of students with 13 unique physical self-description profiles. Two of the three clusters consist of more females than 14 males (Groups 2 and 3). Group 2 has about 85\% of females with a generally low self-description 15 profile; they also had the lowest physical activity participation, compared to the other two 16 clusters. Group 3 is also a female-dominated group (69\% females) with moderate levels of 17 physical self-concept. On the other hand, Group 1 is has more males than females. The typical 18 characteristic of this group is high in sports competence, strength, flexibility, endurance, 19 coordination, appearance, physical activity, general self-concept and self-esteem. Physical

20 activity participation is the highest among this group. The findings of the current study show that 21 the PDSQ-S provides a clear analysis of the unique characteristics of the participants. The LPA 22 shows a clear distinction in all the 11 factors of the PDSQ-S. 
The current study provides evidence that PDSQ-S has adequate internal reliability and

2 discriminant validity. However, convergent validity of the PDSQ-S is questionable and there is a

3 need for more studies to investigate the psychometric properties of the PDSQ-S, particularly with

4 non-English speaking nations.

5 What is clear is that the 11 factors of the PDSQ-S provide three clear distinctive profiles

6 that possess unique characteristics and that the profiles could be differentiated by the levels of

7 physical activity level. Future studies could use the method LPA to design intervention

8 programmes suitable for each profile group (Donovan \& Owen, 1994; Killoran, Cavill, \&

9 Walker, 1994). There are a few limitations of the current study. First, this study is cross-

10 sectional, it is not possible to provide information on trends. A longitudinal design would be

11 required. Second, the participants may respond to the questionnaire in a socially desirable way.

12 Finally, this study lacks objective measures of sedentary and physical activities. Future studies

13 need to consider other more objective measures such as the use of direct observations or

14 pedometers. Another possibility is to consider garnering information from other sources, such as

15 from parents, peers, and teachers to triangulate the findings.

16 In conclusion, the use of LPA in this study shows that it is useful in differentiate groups

17 of students with different physical self-concept. This will help in studying the defining

18 characteristics of important subgroups and consequently intervention programmes can be

19 designed to better target such groups. Given the multidimensional nature of physical self-concept,

20 studying such factors in combination may be fruitful. 


\section{References}

2 Akaike, H. (1987). Factor analysis and the AIC. Psychometrika, 52, 317-332.

3 Bagozzi, P. R., \& Yi, Y. (1988). On the Evaluation of Structural Equation Models. Journal of the $4 \quad$ Academy of Marketing Science, 16(1), 74-94. doi: 10.1007/BF02723327

5 Bagozzi, R. P. (1981). An examination of the validity of two models of attitude. Multivariate Behavioral Research, 16, 323-359. doi: 10.1207/s15327906mbr1603_4

7 Bentler, P. M., \& Wu, E. (1998). EQS for Windows (Version 5.7). Encino, CA: Multivariate Software.

9 Brislin, R. W. (1990). Applied cross-cultural psychology. Newbury Park, CA: Sage.

10 Chung, P. (2003). Physical self-concept between PE major and non-PE major students in Hong $11 \quad$ Kong. Journal of Exercise Science and Fitness, 1(1), 41-46.

12 Cole, D. A. (1987). Utility of confirmatory factor analysis in test validation research. Journal of Consulting and Clinical Psychology, 55(4), 584-594. doi: 10.1037/0022-006X.55.4.584

14 Cronbach, L. J. (1951). Coefficient alpha and the internal structure of tests. Psychometrika, 16, 297-334. doi: 10.1007/BF02310555

16 Dillion, W. R., \& Goldstein, M. (1984). Multivariate Analysis: Methods and applications. New York: Wiley.

18 Donovan, R. J., \& Owen, N. (1994). Social marketing and population interventions. In R. K. Dishman (Ed.), Advances in Exercise Adherence (pp. 249-290). Champaign, IL: Human Kinetics.

21 Fornell, C., \& Larcker, D. (1981). Evaluating structural equation models with unobservable variables and measurement error. Journal of Marketing Research, 18, 39-50. doi: 
1 Fox, K. R. (2000). Self-esteem, self-perceptions, and exercise. International Journal of Sport $2 \quad$ Psychology, 31, 228-240.

3 Harter, S. (1996). Historical roots of contemporary issues involving the self-concept. In B.

$4 \quad$ Bracken (Ed.), Handbook of self-concept (pp. 1-37). New York: Wiley.

5 Hu, L., \& Bentler, P. M. (1999). Curoff criteria for fit indexes in covariance structure analysis:

6 Conventional criteria versus new alternatives. Structural Equation Modeling, 6(1), 1-55.

$7 \quad$ doi: $10.1080 / 10705519909540118$

8 Killoran, A., Cavill, N., \& Walker, A. (1994). Who needs to know what? An investigation of the 9 characteristics of the key target groups for the effective promotion of physical activity in

13 Lo, Y., Mendell, N. R., \& Rubin, D. B. (2001). Testing the number of components in a normal 14 mixture Biometrika, 88, 767-778.

15 MaÔano, C., Ninot, G., \& Bilard, J. (2004). Age and gender effects on global self-esteem and 16 physical self-perception in adolescents. European Physical Education Review, 10(1), 5369. doi: $10.1177 / 1356336 \times 04040621$

18 Marsh, H. W. (1988). The structure of academic self-concept: The Marsh/Shavelson model. Journal of Educational Psychology, 82(4), 623-636. doi: 10.1037/0022-0663.82.4.623

Marsh, H. W. (1996). Positive and negative global self-esteem: A substantively meaningful distinction or artifactors? Journal of Personality \& Social Psychology, 70, 810-819. doi: 
1 Marsh, H. W., Hey, J., Roche, L. A., \& Perry, C. (1997). Structure of physical self-concept: Elite athletes and physical education setudents. Journal of Educational Psychology, 89(2), 369-380. doi=10.1037/0022-0663.89.2.369

Marsh, H. W., Lüdtke, O., Trautwein, U., \& Morin, J. S. A. (2009). Classical latent profile analysis of academic self-concept dimensions: Synergy of person- and variable-centered approaches to theoretical models of self-concept. Structural Equation Modeling, 16, 191225. doi: 10.1080\10705510902751010

Marsh, H. W., Martin, A. J., \& Jackson, S. (2010). Introducing a short version of the Physical Self Description Questionnaire: New strategies, short-form evaluative criteria, and applications of factor analyses. Journal of Sport \& Exercise Psychology, 32, 438-482.

Marsh, H. W., \& Redmayne, R. S. (1994). A multidimensional physical self-concept and its relations to multiple components of physical fitness. Journal of Sport and Exercise Psychology, 16, 43-55.

Marsh, H. W., Richards, G. E., Johnson, S., Roche, L., \& Tremayne, P. (1994). Physical SelfDescription Questionnaire: Psychometric properties and a multitrait-multimethod analysis of relations to existing instruments. Journal of Sport and Exercise Psychology, $16,270-305$.

Monthuy-Blanc, J., Maïano, C., Morin, A. J., \& Stephan, Y. (2012). Physical self-concept and disturbed eating attitudes and behaviors in French athlete and non-athlete adolescent girls: direct and indirect relations. Body Image, 9(3), 373-380. doi:

10.1016/j.bodyim.2012.04.005 
1 Muthén, B. (2001). Latent variable mixture modeling. . In G. A. Marcoulides \& R. E. Schumacker (Eds.), New Developments and Techniques in Structural Equation Modeling (pp. 1-33). Magwah, NJ: Lawrence Erlbaum Associates.

Muthén, L. K., \& Muthén, B. O. (2004). MPlus: Version 4.2. Los Angeles: Muthén \& Muthén.

Nunnally, J. C., \& Bernstein, I. H. (1994). Psychometric theory (3rd ed.). New York: McGrawHill, Inc.

Paradise, A. W., \& Kernis, M. H. (2002). Self-esteem and Psychological Well-being: Implications of Fragile Self-esteem. Journal of Social and Clinical Psychology, 21, 345361. doi: 10.1521/jscp.21.4.345.22598

Pastor, D. A., Barron, K. E., Miller, B. J., \& Davis, S. L. (2007). A latent profile analysis of college students' achievement goal orientation. Contemporary Educational Psychology, 32, 8-47. doi: 10.1016/j.cedpsych.2006.10.003

Raykov, T. (1998). A method for obtaining standard errors and confidence intervals of composite reliability for congeneric measures. Applied Psychological Measurement, 22, 369-374. doi: $10.1177 / 014662169802200406$

Schwartz, G. (1978). Estimating the dimension of a model. Annals of Statistics, 6, 461-464. doi: $10.1214 / \mathrm{aos} / 1176344136$

Shavelson, R. J., Hubner, J. J., \& Stanton, G. C. (1976). Self-concept: Validation of construct interpretations. Review of Educational Research, 46, 407-441. doi: $10.3102 / 00346543046003407$

Sonstroem, R. J., Harlow, L. L., \& Josephs, L. (1994). Exercise and self-esteem: Validity of model expansion and exercise associations. Journal of Sport and Exercise Psychology, 16, 29-42. 
1 Spence, J. C., McGannon, K. R., \& Poon, P. (2005). The effect of exercise on global self-esteem:

2 a quantitative review. Journal of Sport and Exercise Psychology 27(3), 311-334.

3 Van Vorst, J. G., Buckworth, J., \& Mattern, C. (2002). Physical self-concept and strength

4 changes in college weight training classes. Research Quarterly in Exercise and Sport, 73, 5 113-117. DOI:10.1080/02701367.2002.10608998 
Table 1

Descriptive Statistics and Reliability Coefficients of the PDSQ-S Scale

\begin{tabular}{lccccccc}
\hline SubScale & $M$ & $S D$ & Skewness & Kurtosis & Cronbach's $\alpha$ & $\begin{array}{c}\text { Composite } \\
\text { Reliability }\end{array}$ & AVE \\
\hline Physical Activity & 2.98 & 1.17 & .08 & -1.00 & .70 & .68 & .52 \\
Appearance & 3.22 & .99 & -.06 & -.44 & .80 & .82 & .61 \\
Body Fat & 2.66 & 1.15 & -.56 & -.71 & .86 & .79 & .56 \\
Coordination & 3.56 & .83 & -.30 & -.43 & .75 & .72 & .37 \\
Endurance & 3.05 & 1.02 & .13 & -.82 & .76 & .64 & .38 \\
Self-Esteem & 3.62 & .76 & -.26 & -.33 & .71 & .64 & .31 \\
Flexibility & 3.36 & 1.03 & -.18 & -.84 & .79 & .68 & .42 \\
General Self-Concept & 3.59 & .92 & -.37 & -.45 & .80 & .65 & .38 \\
Health & 4.04 & .85 & -.79 & -.12 & .76 & .74 & .38 \\
Sport Competence & 3.22 & 1.17 & -.07 & -1.08 & .88 & .83 & .43 \\
Strength & 3.67 & .88 & -.40 & -.25 & .71 & .65 & .38 \\
\hline
\end{tabular}


Table 2

Latent Factor Correlations for the PSDQ-S Scales and Discriminant Validity Information

\begin{tabular}{|c|c|c|c|c|c|c|c|c|c|c|}
\hline Variable & 1 & 2 & 3 & 4 & 5 & 6 & 7 & 8 & 9 & 10 \\
\hline 1. Physical activity & - & & & & & & & & & \\
\hline 2. Appearance & $\begin{array}{c}.42^{*} \\
(.020) \\
{[.38, .46]}\end{array}$ & -- & & & & & & & & \\
\hline 3. Body fat & $\begin{array}{c}.26^{*} \\
(.014) \\
{[.23, .29]}\end{array}$ & $\begin{array}{c}.30^{*} \\
(.046) \\
{[.21, .39]}\end{array}$ & -- & & & & & & & \\
\hline 4. Coordination & $\begin{array}{c}.71^{*} \\
(.023) \\
{[.66, .76]}\end{array}$ & $\begin{array}{c}.52^{*} \\
(.035) \\
{[.45, .59]}\end{array}$ & $\begin{array}{c}.36^{*} \\
(.035) \\
{[.29, .43]}\end{array}$ & -- & & & & & & \\
\hline 5. Endurance & $\begin{array}{l}.81^{*}(.041) \\
{[.73, .89]}\end{array}$ & $\begin{array}{l}.39^{*}(.044) \\
{[.30, .48]}\end{array}$ & $\begin{array}{l}.33^{*}(.048) \\
{[.24, .43]}\end{array}$ & $\begin{array}{l}.73^{*}(.041) \\
{[.65, .81]}\end{array}$ & -- & & & & & \\
\hline 6. Self-esteem & $\begin{array}{c}.50^{*} \\
(.018) \\
{[.46, .54]}\end{array}$ & $\begin{array}{c}.54^{*} \\
(.038) \\
{[.46, .62]}\end{array}$ & $\begin{array}{c}.24^{*} \\
(.034) \\
{[.17, .31]}\end{array}$ & $\begin{array}{c}.64^{*} \\
(.032) \\
{[.58, .70]}\end{array}$ & $\begin{array}{c}.48^{*} \\
(.041) \\
{[.40, .56]}\end{array}$ & -- & & & & \\
\hline 7. Flexibility & $\begin{array}{c}.69^{*} \\
(.030) \\
{[.63, .75]}\end{array}$ & $\begin{array}{c}.61^{*} \\
(.045) \\
{[.52, .70]}\end{array}$ & $\begin{array}{c}.49^{*} \\
(.047) \\
{[.40, .58]}\end{array}$ & $\begin{array}{c}.89^{*} \\
(.044) \\
{[.80, .98]}\end{array}$ & $\begin{array}{l}.78^{*} \\
(.053) \\
{[.67, .88]}\end{array}$ & $\begin{array}{l}.64^{*} \\
(.039) \\
{[.56, .72]}\end{array}$ & -- & & & \\
\hline $\begin{array}{l}\text { 8. General self- } \\
\text { concept }\end{array}$ & $\begin{array}{c}.58^{*} \\
(.025) \\
{[.53, .63]}\end{array}$ & $\begin{array}{c}.66^{*} \\
(.049) \\
{[.56, .76]}\end{array}$ & $\begin{array}{c}.66^{*} \\
(.058) \\
{[.55, .77]}\end{array}$ & $\begin{array}{c}.71^{*} \\
(.039) \\
{[.63, .79]}\end{array}$ & $\begin{array}{c}.59^{*} \\
(.048) \\
{[.49, .69]}\end{array}$ & $\begin{array}{c}.66^{*} \\
(.041) \\
{[.58, .74]}\end{array}$ & $\begin{array}{c}.84^{*} \\
(.051) \\
{[.74, .94]}\end{array}$ & -- & & \\
\hline 9. Health & $\begin{array}{c}.23^{*} \\
(.005) \\
{[.22, .24]}\end{array}$ & $\begin{array}{c}.20^{*} \\
(.031) \\
{[.14, .26]}\end{array}$ & $\begin{array}{c}.10 \\
(.032) \\
{[.04, .16]}\end{array}$ & $\begin{array}{c}.39^{*} \\
(.028) \\
{[.33, .45]}\end{array}$ & $\begin{array}{c}.30^{*} \\
(.039) \\
{[.22,38]}\end{array}$ & $\begin{array}{c}.35^{*} \\
(.027) \\
{[.30, .40]}\end{array}$ & $\begin{array}{c}.30^{*} \\
(.033) \\
{[.23, .37]}\end{array}$ & $\begin{array}{c}.19^{*} \\
(.032) \\
{[.13, .25]}\end{array}$ & -- & \\
\hline 10. Competence & $\begin{array}{l}.83^{*} \\
(.047) \\
76 \quad 921\end{array}$ & $\begin{array}{l}.41^{*} \\
(.046)\end{array}$ & $\begin{array}{l}.36^{*} \\
(.050) \\
06 \quad 46]\end{array}$ & $\begin{array}{l}.79^{*} \\
(.047) \\
70 \quad 88]\end{array}$ & $\begin{array}{l}.88^{*} \\
(.059)\end{array}$ & $\begin{array}{c}.49^{*} \\
(.042) \\
41 \quad 571\end{array}$ & $\begin{array}{l}.78^{*} \\
(.052) \\
68 \quad 88]\end{array}$ & $\begin{array}{l}.66^{*} \\
(.054) \\
{[5577]}\end{array}$ & $\begin{array}{l}.35^{*} \\
(.042) \\
{\left[\begin{array}{ll}27 & 43]\end{array}\right.}\end{array}$ & -- \\
\hline 11. Strength & $\begin{array}{c}.77^{*} \\
(.034) \\
{[.70, .84]}\end{array}$ & $\begin{array}{c}.50^{*} \\
(.044) \\
{[.41, .59]}\end{array}$ & $\begin{array}{c}.06 \\
(.044) \\
{[-.03, .15]}\end{array}$ & $\begin{array}{c}.79^{*} \\
(.041) \\
{[.71, .87]}\end{array}$ & $\begin{array}{l}.85^{*} \\
(.055) \\
{[.74, .96]}\end{array}$ & $\begin{array}{c}.63^{*} \\
(.041) \\
{[.55, .71]}\end{array}$ & $\begin{array}{c}.78^{*} \\
(.050) \\
{[.68, .88]}\end{array}$ & $\begin{array}{c}.61^{*} \\
(.046) \\
{[.52, .70]}\end{array}$ & $\begin{array}{c}.56^{*} \\
(.044) \\
{[.47, .65]}\end{array}$ & $\begin{array}{c}.86^{*} \\
(.057) \\
{[.76, .96]}\end{array}$ \\
\hline
\end{tabular}

${ }^{*} p<.05$

Note: In each cell, first row $=$ latent factor correlation, second row $=$ SE of latent correlation coefficient, last row $=$ correlation $90 \%$ confidence intervals within plus/minus two SE. 
Table 3

Latent Profile Fit Statistics

\begin{tabular}{ccccccccc}
\hline \multirow{2}{*}{$\begin{array}{c}\text { No. } \\
\text { Group }\end{array}$} & $\begin{array}{c}\text { No. } \\
\text { Parameter }\end{array}$ & AIC & BIC & SSA-BIC & pLMR & Entropy & \multicolumn{2}{c}{ Group Sizes } \\
\hline 1 & 22 & 22797.30 & 22898.77 & 22828.91 & --- & & 0 & 0 \\
2 & 34 & 20565.50 & 20722.30 & 20614.34 & .001 & .896 & 0 & 0 \\
3 & 46 & 20101.06 & 20313.21 & 20167.14 & .001 & .852 & 0 & 0 \\
4 & 58 & 19929.22 & 20196.92 & 20012.14 & .091 & .819 & 0 & 0 \\
5 & 70 & 19779.57 & 20101.41 & 19880.14 & .167 & .813 & 0 & 0 \\
6 & 82 & 19699.71 & 20077.90 & 19817.52 & .123 & .816 & 0 & 0 \\
7 & 94 & 19633.22 & 20066.75 & 19768.26 & .546 & .794 & 0 & 0 \\
8 & 106 & 19570.30 & 20059.18 & 19722.59 & .289 & .796 & 0 & 1 \\
\hline
\end{tabular}

Note. AIC $=$ Akaike's Information Criterion, BIC $=$ Bayesian Information Criterion, SSA-BIC $=$ sample-size adjusted BIC, pLMR $=$ Lo-Mendell-and Rubin likelihood ratio test, $\mathrm{LT}=$ less than. 
Table 4

Comparison of the Three-cluster Profiles on Outcome Variables

\begin{tabular}{lccc}
\hline & $\begin{array}{c}\text { Cluster 1 } \\
(\mathrm{N}=260)\end{array}$ & $\begin{array}{c}\text { Cluster 2 } \\
(\mathrm{N}=130)\end{array}$ & $\begin{array}{c}\text { Cluster 3 } \\
(\mathrm{N}=354)\end{array}$ \\
\hline Duration & $1.96^{*}(.96)_{\mathrm{a}}$ & $1.32^{*}(.65)_{\mathrm{b}}$ & $1.53^{*}(.70)_{\mathrm{c}}$ \\
Frequency & $2.70^{*}(.97)_{\mathrm{a}}$ & $1.68^{*}(.76)_{\mathrm{b}}$ & $2.08^{*}(.89)_{\mathrm{c}}$ \\
\hline
\end{tabular}

Note. Means in the same row that do not share superscripts differ at $p<.05$, using Tukey’s HSD. 


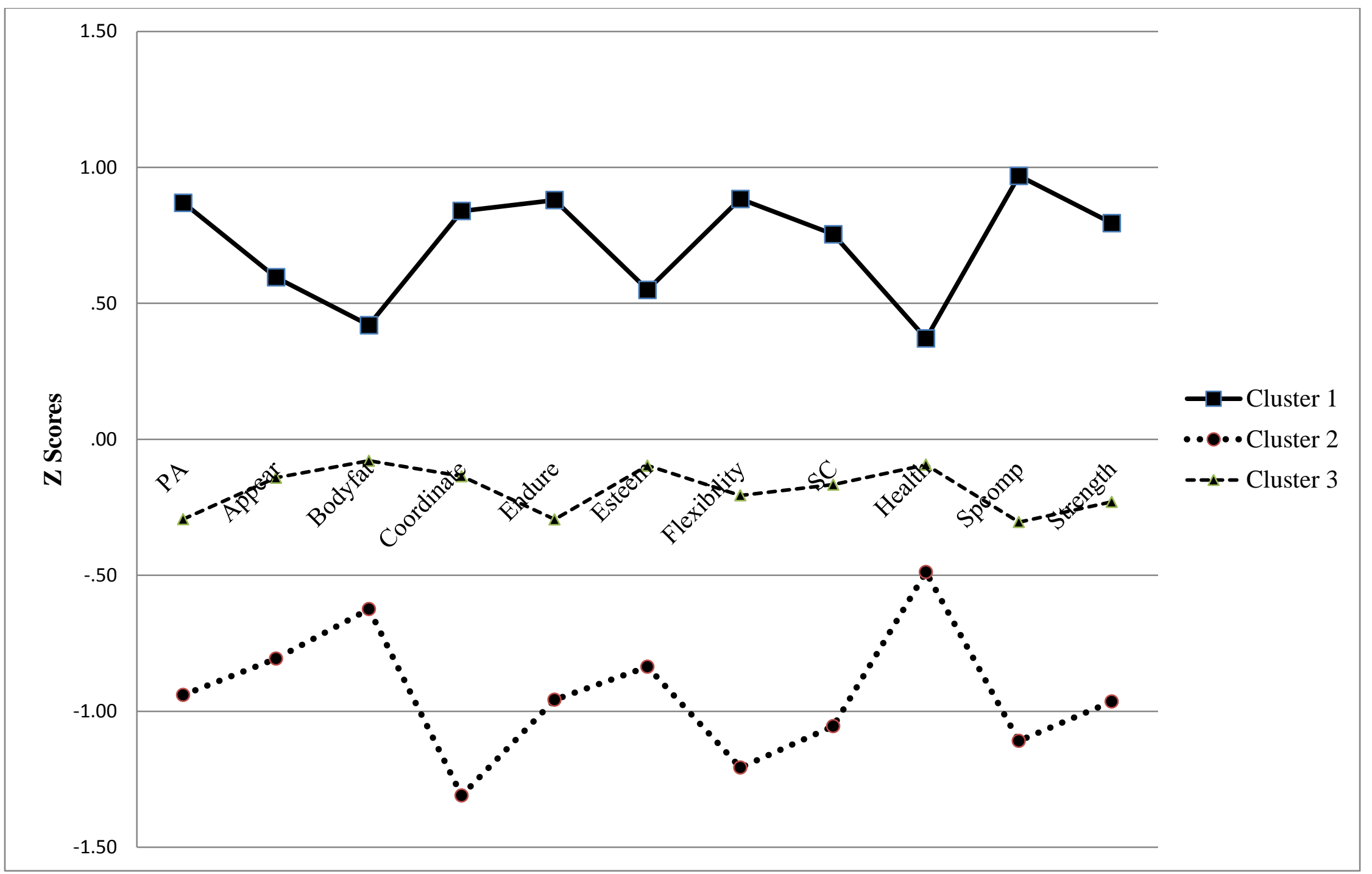

Figure 1. Graphical representation of the three cluster profiles. 